\title{
Numerical and experimental investigation on the ballast flushing system
}

\author{
Han Yuan ${ }^{*}$, Peilin Zhou ${ }^{2}$ and Ning Mei ${ }^{1}$ \\ 1. College of Engineering, Ocean University of China, 238 Songling Road, Laoshan \\ district, Qingdao 266100, China \\ 2. Department of Naval Architecture and Marine Engineering, University of \\ Strathclyde, Glasgow G4 OLZ, United Kingdom \\ Phone/Fax: +86-532-66781105, \\ E-mail: hanyuan@ouc.edu.cn \\ Address: 238 Songling Road, Laoshan district, Qingdao 266100, China
}

\begin{abstract}
The ballast sediments deposit not only provide the breeding ground for the survival organisms, but also affect the weight balance of the ship and even accelerate the corrosion of the ballast tank. In this work the performance of a ballast water flushing system for the $138,000 \mathrm{~m}^{3}$ LNGC (Liquefied Natural Gas Carrier) double bottom cargo ship is studied. A simulation model of the ballast tank was made to conduct the numerical analysis. Besides, a scaled experimental setup was established on basis of the similarity principle. With different injecting velocities at the flushing inlet, the sediments distribution in the ballast tank is investigated and the energy consumption of the circulating pump is studied. The results show that by flushing the ballast water on the bottom, the sediments first accumulate at the far end, with the sediments volume fraction climbs up to $10-30 \%$, before gradually getting removed over time. Further, higher inlet velocity leads to a more rapid decrease of average sediments
\end{abstract}


proportion in the ballast tank over time, but the energy consumption in circulating pump significantly increases as well. The required power for this proposed ballast water flushing system is within the common range and thus applicable in the cargo ship.

Keywords: Ballast water; sediments; flushing; CFD.

\section{Introduction}

Negative environmental impacts made by the uptake and discharge of ballast water are great challenge for international shipping. The non-indigenous species (NIS) transported in the ballast tank may cause harm to native ecosystems $[1,2]$ and these invasive species can even contribute to animal extinctions in local area [3-5]. In response to this challenge, the International Maritime Organization (IMO) instituted a performance standard of "Regulation D-2" for ballast water treatment management [6-8]. In this regulation, limitations on both the size and the quantity of the remained organisms in the treated ballast water are made to exclude microbes and viable microorganisms from discharged ballast water [9]. To meet the requirement of the IMO convention, different sorts of ballast water management technologies including oxidation by chlorine/ozone and the ultraviolet radiation (UV) method are proposed by researchers.

Although dozens of shipboard treatment systems have been certified as meeting ballast water discharge standards till now, their application in eliminating invasive species is not that satisfactory[10,11]. It should be noted that only the maximum amount of living organisms is restricted according to Regulation D-2, nevertheless, 
the remaining sediments in the ballast water is still not concerned. Studies in references $[12,13]$ pointed out that the soil sediments mainly consist of the clay, silt and sand, with the particle diameter from less than $2 \mu \mathrm{m}$ to $2 \mathrm{~mm}$. Moreover, these soil sediments are admitted with ballast water during the ballasting. Although most of the large-size organisms $(>10 \mu \mathrm{m})$ gets inactivated according to Regulation D-2, a tiny fraction of organisms cannot be totally removed from the loaded ballast water, and these soil sediments turn to be the perfect breeding ground for the survival organisms [14-16].

In fact, providing the habitat for organisms is only part of negative impacts that the ballast water sediments could induce. On one hand, it is found that The sediments at the bottom of the ballast tanks in a double hull cargo vessel can accumulate up to 30 cm depth within only two years operation [17]. According to current Rules and Regulations of respective Classification Societies, sediments in ballast water tank can only be systematically removed during the mandatory dry docking, and the interval is usually made in every five years [18]. With such a long period of time the sediments tend to be compacted and the sediments removing work becomes a great challenge. On the other hand, the ballast sediments also affect the weight balance of the ship. Due to non-uniform distribution in the ballast tanks, the loading and unloading of ballast have to be cautious, because the excessive stresses can potentially lead to a ship breaking during incorrectly unloading [19].

Furthermore, the corrosion of the ballast tank is another negative impact induced by the ballast sediments. The sulphate reducing bacteria (SRB) and acid producing bacteria (APB) that living in the sediments can bring significant microbiologically influenced corrosion (MIC) [20, 21]. Compared with the electrochemical oxidation process, the corrosion speed of MIC is greatly accelerated and thus unpredictable. 
73 This paper proposed a solution for this problem. With the flushing system, the unfiltered sediments along with the regrown organisms can be removed when needed

In this paper, a ballast water flushing system is proposed. By circulating the ballast water in the tank, the deposits of sediments can be suspended and removed before getting compacted on the tank bottom. A simulation model of the ballast tank was made; an experimental setup was established on basis of the similarity principle. Further, with four different ejecting velocities, both numerical and experimental studies were conducted to evaluate the performance of this flushing system.

\section{System description}

In this work the ballast water system of the $138,000 \mathrm{~m}^{3}$ LNGC (Liquefied Natural Gas Carrier) double bottom cargo ship [22] is investigated. The volume of cargo ballast water system takes up to $56,090 \mathrm{~m}^{3}$ in total. Figure 1 shows the structure of a single block of ballast tank in the cargo ship. As is shown, lines of longitudinal are arranged on the inner side of the ballast tank and drain holes are provided on the bottom longitudinal. Besides, the ballast water pipes (inlet-pipe and outlet-pipe) are arranged in the corner, on which a row of jet holes (inlets) are placed along the inflow-pipe while a row of exit holes (outlets) are placed along the outflow-pipe. Besides, a hydrocyclone [23] is introduced between the outflow-pipe and the circulating pump to separate the sediments from the ballast water. The size of a single block of ballast tank is $6700 \times 3000 \times 2000(\mathrm{~mm})$, and the size of inlets/outlets on the ballast water pipes is $100 \times 10(\mathrm{~mm})$. 
95 With the assistance of the circulating pump, the ballast water is first pumped into the inflow-pipe and then ejected through the inlets, and in this way the deposits of sediments are stirred up. Further, the suspended sediments, along with the ballast water, get sucked into the outflow-pipe through the outlets. Then the mixture of water and sediments is separated in the hydrocyclone before pumped back into the ballast tank. As ballast water flows into the hydrocyclone, a cyclonic flow is produced and the centrifugal force drives the sediments toward the outer wall, so the clean water can flow through the centre of the hydrocyclone into the circulating pump. Thus the ballast water circulates around the ballast tank and the bottom sediments deposits are suspended and then removed from the ballast water.

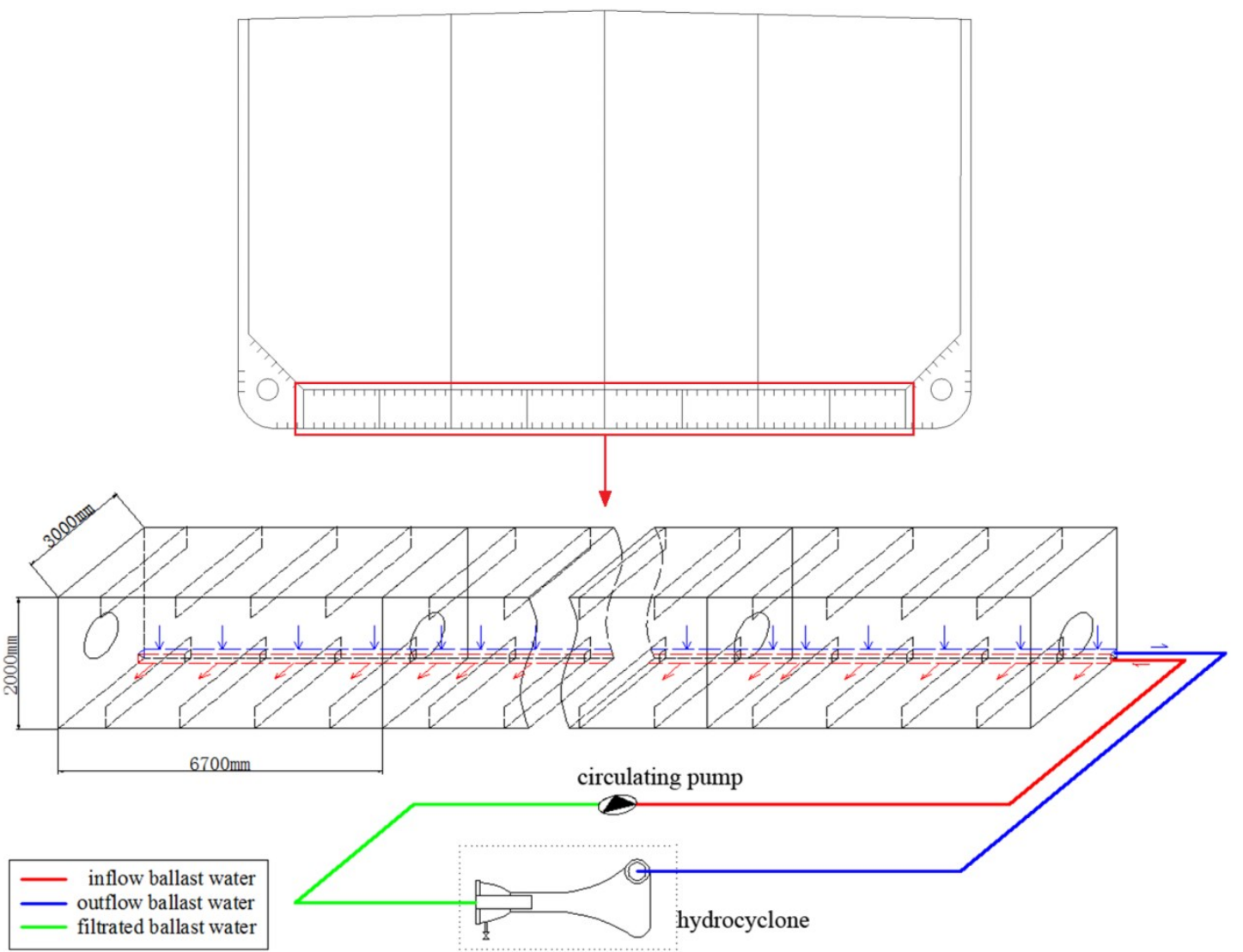




\section{Simulation setup}

The numerical model for the ballast tank consists of a row of inlets along the inflowpipe, a row of outlets along the outflow-pipe and longitudinal with drain holes on the inner side of the tank, as shown in Figure 2.

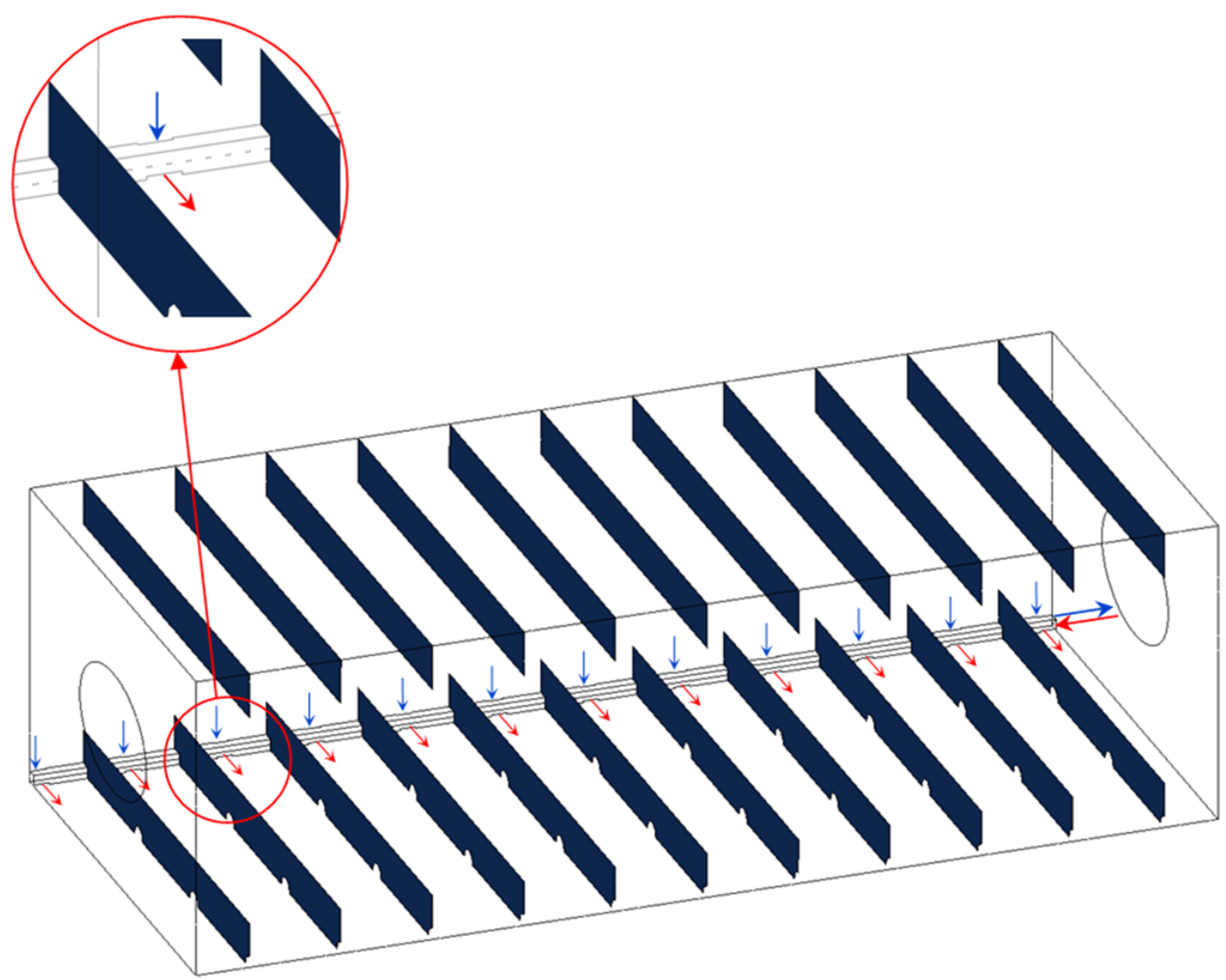

Figure 2 Ballast tank model for simulation

\subsection{Modelling equations}

The mixture model, a kind of Eular-Eular multiphase model, is used in this simulation.

The two phases of water and sediment are treated as interpenetrating continua in the mixture model. Besides, the momentum and continuity equations of the mixture and the volume fraction equations of the secondary phase are solved. Compared with a 
134 The continuity equation is given as follow:

$135 \frac{\partial}{\partial t}\left(\rho_{m}\right)+\frac{\partial}{\partial x_{i}}\left(\rho_{m} u_{m}\right)=0$

136 The momentum equation for the mixture is given as follow: appropriate for current simulation.

Governing equations:

full Eulerian multiphase model, the mixture model is simpler, and more suitable for the cases that the interphase laws are unknow. Simultaneously, the RNG $k-\varepsilon$ model is selected as the turbulence model for the simulation. The RNG (Renormalization Group) $k-\varepsilon$ model is a refined Standard $k-\varepsilon$ model, which is also derived from the instantaneous Navier-Stoke equations and follows the $k-\varepsilon$ (turbulent kinetic energy and dissipation rate) two equations turbulence modelling framework. But compared with the Standard $k-\varepsilon$ model, the RNG $k-\varepsilon$ model introduces more terms of dissipation in transport equation, which make it more accurate for rapidly strained flows and swirling flows. Besides, this model accounts for low-Reynolds-number effects and provides not constant values but an analytical formula for turbulent Prandtl numbers. All of these refinements make the RNG $k-\varepsilon$ model more

\footnotetext{
The momentum equation for the mixture is given as follow:
}

$\left.137 \frac{\partial}{\partial t}\left(\rho_{m} \underset{u_{m}}{\mathrm{r}}\right)+\frac{\partial}{\partial x_{j}}\left(\rho_{m} \underset{u_{m}}{\stackrel{\mathrm{r}}{\mathrm{r}}}\right)_{m}\right)=-\frac{\partial p}{\partial x_{i}}+\frac{\partial}{\partial x_{j}}\left[\mu_{m}\left(\frac{\partial}{\partial x_{i}} \underset{u_{m}}{\mathrm{r}}+\frac{\partial}{\partial x_{j}} \underset{u_{m}}{\mathrm{r}}\right)\right]+\rho_{m} \underset{g}{\mathrm{r}}-\frac{\partial}{\partial x_{j}}\left[\rho_{m} \overline{u_{i}^{\prime} u_{j}^{\prime}}\right]$

138 Where $\dot{u}_{m}$ is the mass-averaged velocity, $\rho_{m}$ is the mixture density, $\alpha_{s}$ and $\alpha_{f}$ are the

139 volume fraction of water phase and sediment phase, respectively, $\mu_{m}$ is the viscosity 
140 of the mixture, $u_{i}^{\prime}$ is the turbulent velocity fluctuation. These terms can be written as

141 follows:

142

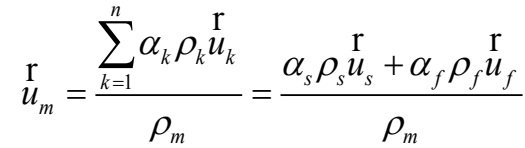

$143 \rho_{m}=\alpha_{s} \rho_{s}+\alpha_{f} \rho_{f}$

$144 \quad \mu_{m}=\alpha_{s} \mu_{s}+\alpha_{f} \mu_{f}$

$145 \quad \alpha_{s}+\alpha_{f}=1$

146 Moreover, the Reynolds-stress tensor $-\rho_{m} \overline{u_{i}^{\prime} u_{j}^{\prime}}$ can be written as:

$147-\rho_{m} \overline{u_{i}^{\prime} u_{j}^{\prime}}=-\frac{2}{3} \rho_{m} k \delta_{i j}+\mu_{t}\left(\frac{\partial}{\partial x_{i}} \underset{u_{m}}{\mathrm{r}}+\frac{\partial}{\partial x_{j}} \stackrel{\mathrm{r}}{u_{m}}\right)$

$148 \quad \mu_{t}=C_{\mu} \rho_{m} \frac{k^{2}}{\varepsilon}$

149 Where $k$ is the turbulent kinetic energy, $\varepsilon$ is the turbulent dissipation rate, $\delta_{i j}$ is the

150 Kronecker delta. $\mu_{t}$ is the eddy viscosity, $C_{\mu}$ is a constant.

151 In addition, the momentum equation for the mixture is not closed unless the

152 Reynolds-stress tensor term is provided. This term can be obtained with assistance of

153 the turbulence model shown as follow.

154 The transport equations for the RNG $k-\varepsilon$ model can be described as follows:

$155 \frac{\partial}{\partial t}(\rho k)+\frac{\partial}{\partial x_{j}}(\rho k u)=\frac{\partial}{\partial x_{i}}\left(\alpha_{k} \mu_{e f f} \frac{\partial}{\partial x_{i}} k\right)+G_{k}+G_{b}-\rho \varepsilon$ 
$156 \frac{\partial}{\partial t}(\rho \varepsilon)+\frac{\partial}{\partial x_{j}}(\rho \varepsilon u)=\frac{\partial}{\partial x_{i}}\left(\alpha_{\varepsilon} \mu_{e f f} \frac{\partial}{\partial x_{i}} \varepsilon\right)+C_{1 \varepsilon} \frac{\varepsilon}{k}\left(G_{k}+C_{3 \varepsilon} G_{b}\right)-C_{2 \varepsilon} \rho \frac{\varepsilon^{2}}{k}-R_{\varepsilon}$

157 Where

$158 \mu_{e f f}=\mu+\mu_{t}$

$159 G_{k}=\mu_{t} S^{2}$

$160 S=\sqrt{2 S_{i j} S_{i j}}$

$161 \quad S_{i j}=\frac{1}{2}\left(\frac{\partial}{\partial x_{i}} \stackrel{\mathrm{r}}{u_{m}}+\frac{\partial}{\partial x_{j}} \stackrel{\mathrm{r}}{u_{m}}\right)$

162 In the $k-\varepsilon$ equations, $G_{k}$ is the generation of turbulence kinetic energy due to the

163 mean velocity gradients, $G_{b}$ is the generation of turbulence kinetic energy due to

164 buoyancy, which is neglected in this simulation, $\alpha_{k}$ and $\alpha_{\varepsilon}$ are the inverse effective

165 Prandtl numbers for $k$ and $\varepsilon, \mu_{e f f}$ is the effective viscosity, $C_{1 \varepsilon}, C_{2 \varepsilon}$ and $C_{3 \varepsilon}$ are

166 turbulence model constants.

$167 R_{\varepsilon}$ is the effects of rapid strain and streamline curvature, which reflects the main

168 difference between the RNG and standard $k-\varepsilon$ model. It can be written as:

$169 \quad R_{\varepsilon}=\frac{C_{\mu} \eta^{3}\left(1-\eta / \eta_{0}\right)}{1+\beta \eta^{3}} \frac{\varepsilon^{2}}{k}$

170 Where

$171 \quad \eta=\frac{k}{\varepsilon} S$

172 In the simulation, the values of above constants are taken as: $\alpha_{k}=\alpha_{\varepsilon}=1.39, \beta=0.012$,

$173 \eta_{0}=4.38, C_{1 \varepsilon}=1.42, C_{2 \varepsilon}=1.68, C_{3 \varepsilon}=0, C_{\mu}=0.0845$. 


\subsection{Simulation method validation}

175 The sedimentation of sediments in the tank is a classic problem, which has been 176 extensively studied [24-28]. Therefore in this section, the reliability of above 177 mathematic model for sedimentation simulation is validated by selecting the 178 sedimentation tank in Ref. [24] as the research object. The geometry of the 179 sedimentation tank for the simulation is based on the experiment. The tank is a 180 rectangular one, with the length of $200 \mathrm{~cm}$, width of $50 \mathrm{~cm}$ and height of $31 \mathrm{~cm}$. The inlet height is $10 \mathrm{~cm}$ and the weir height is $30 \mathrm{~cm}$. The flow field and sediment concentration of the sedimentation tank is simulated by utilizing the RNG $k-\varepsilon-$ mixture model in this paper. The boundary condition and initial condition in this simulation is assigned the same as that in the experimental research in Ref. [24]. The simulation results are compared with the experimental results, shown in Figure 3. It is found that the numerical simulation results show a good match with the experimental results. Both the flow field and the sediment concentration distribution of the sedimentation tank are well predicted, which indicates that the turbulence model and multiphase model utilized in this study is adaptable for the sedimentation simulation.
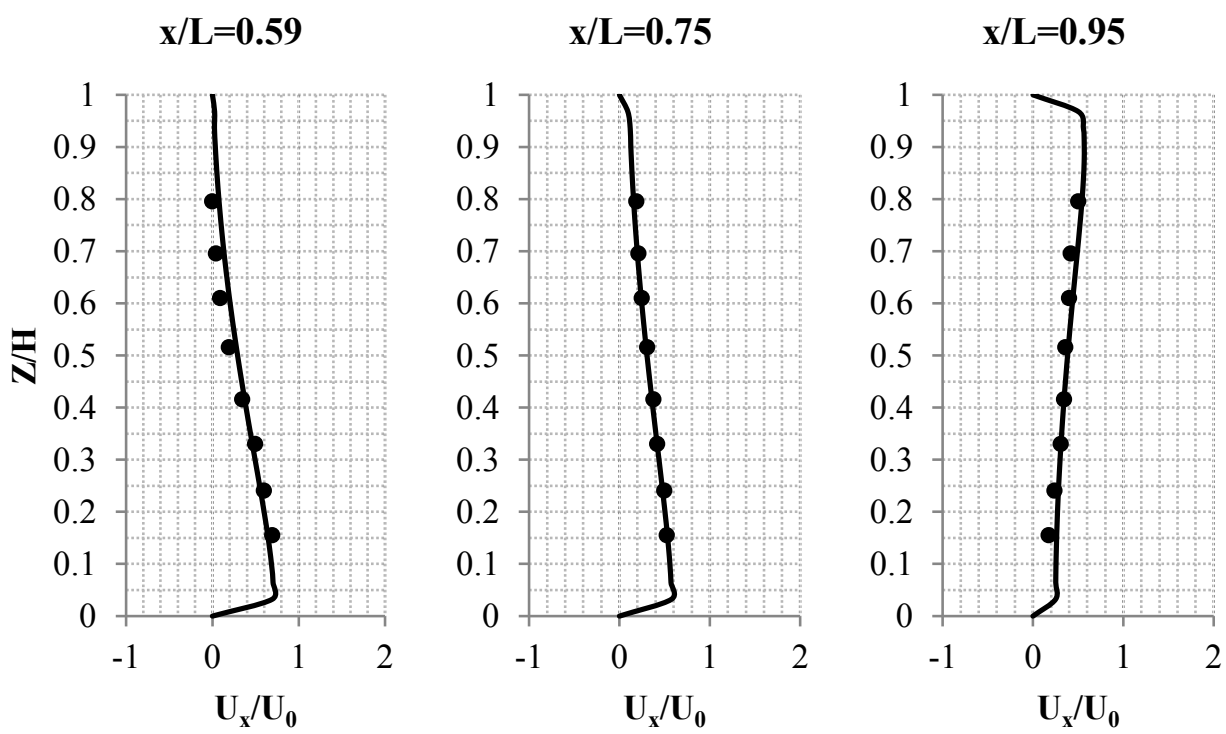


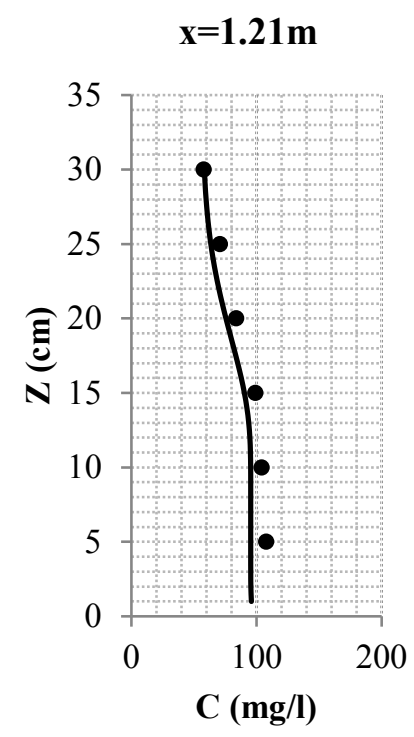

192
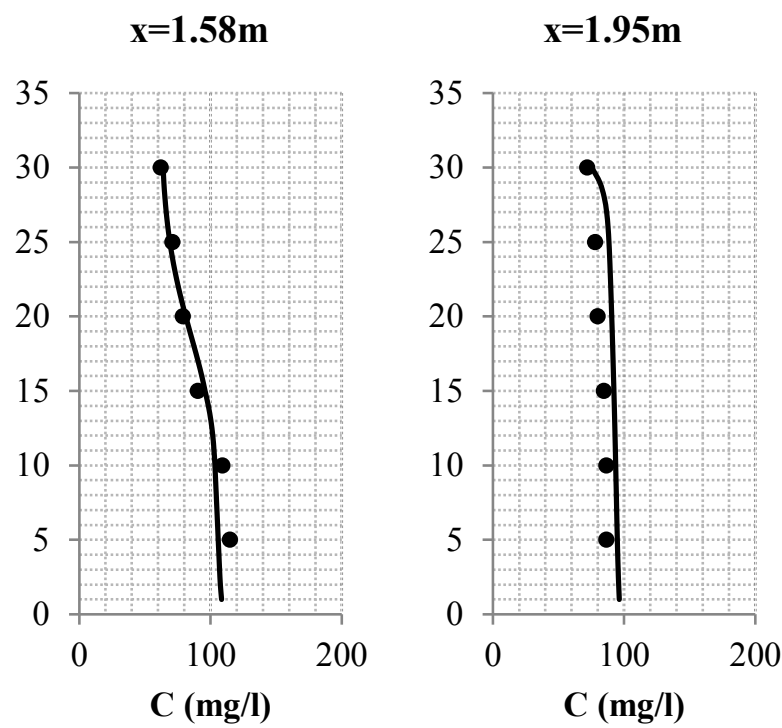

(b)

- Simulation result with proposed mathematic model

- Experimental result in Ref. [20]

Figure 3 Comparison of simulation and experimental results: (a) dimensionless $\mathrm{x}$ velocity of suspended sediments; (b) vertical distribution concentration of suspended sediments at different locations

\subsection{Initial conditions and boundary conditions}

It is known that the thickness of accumulated sediment in the ballast tank varies from a few millimetres to several centimetres, but in most tanks is less than 50mm [29, 30]. Meanwhile, according to A. Tamburini [31, 32], the initial sediments volume fraction on the bottom is experimentally measured at approximately $60 \%$, so in this simulation, the thickness of accumulated sediments on the vessel bottom is assumed to be $20 \mathrm{~mm}$ and the initial sediments volume fraction is made at $60 \%$. Moreover, based on the experimental data, the measured bulk density of sediments is made at $1500 \mathrm{~kg} / \mathrm{m}^{3}$ and the median particle diameter is $11.64 \mu \mathrm{m}$. The density of seawater is $1025 \mathrm{~kg} / \mathrm{m}^{3}$. Besides, the magnitude of the gravitational acceleration is $9.8 \mathrm{~m} / \mathrm{s}^{2}$. Further, in the 
simulation, the velocity-inlet boundary condition is assigned for the inlets on the inflow-pipe. The magnitude of the inlet velocities are assigned at 4 constant values (at $5 \mathrm{~m} / \mathrm{s}, 10 \mathrm{~m} / \mathrm{s}, 15 \mathrm{~m} / \mathrm{s}, 20 \mathrm{~m} / \mathrm{s}$, respectively) and the velocity direction is normal to the inlet face. Besides, the pressure-outlet boundary condition is applied for the outlets on the outflow-pipe.

\subsection{Monitoring plane and lines for simulation model}

A monitoring plane is used to obtain the sediments distribution of the ballast water.

Since the sediments are flushed and suspended by the ejected water along the ballast tank bottom from left corner to right corner, the right corner sediments would be the latest removed. Thus, 5 monitoring lines locate in the bottom right corner are used to evaluate the suspending condition of the ballast tank. The location of these 5 monitoring lines are assigned at $\mathrm{z}=0 \mathrm{~mm}, 10 \mathrm{~mm}, 20 \mathrm{~mm}, 30 \mathrm{~mm}$ and $40 \mathrm{~mm}$, among which lines of $\mathrm{z}=0 \mathrm{~mm}, 10 \mathrm{~mm}$ and $20 \mathrm{~mm}$ are located in the initial sediments layer and lines of $\mathrm{z}=30 \mathrm{~mm}$ and $40 \mathrm{~mm}$ are located above the initial sediments layer. These

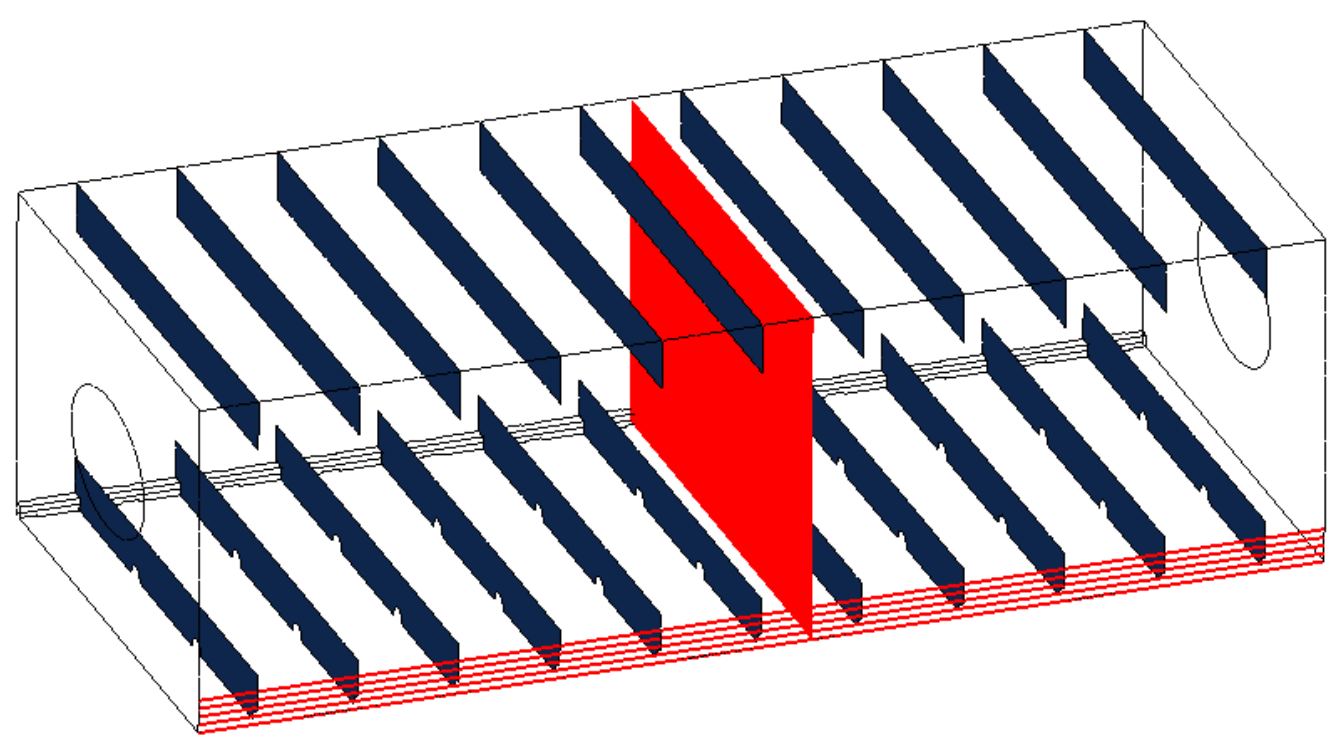




\section{Experimental setup}

\subsection{Test bench description}

227 A 1:10 scaled model of an acrylic ballast tank unit along with the test system was constructed, shown in Figure 5. The bottom sediment in the ballast tank is continuously flushed by the seawater that pumped from the seawater tank. The outflow ballast water is then collected in the sediments tanks. In the experiments, the

231 injecting velocity of seawater at the inlet is controlled by the volume flow rate that monitored with a flow meter. Further, a camera is used to monitor the sediments distribution in the ballast tank.
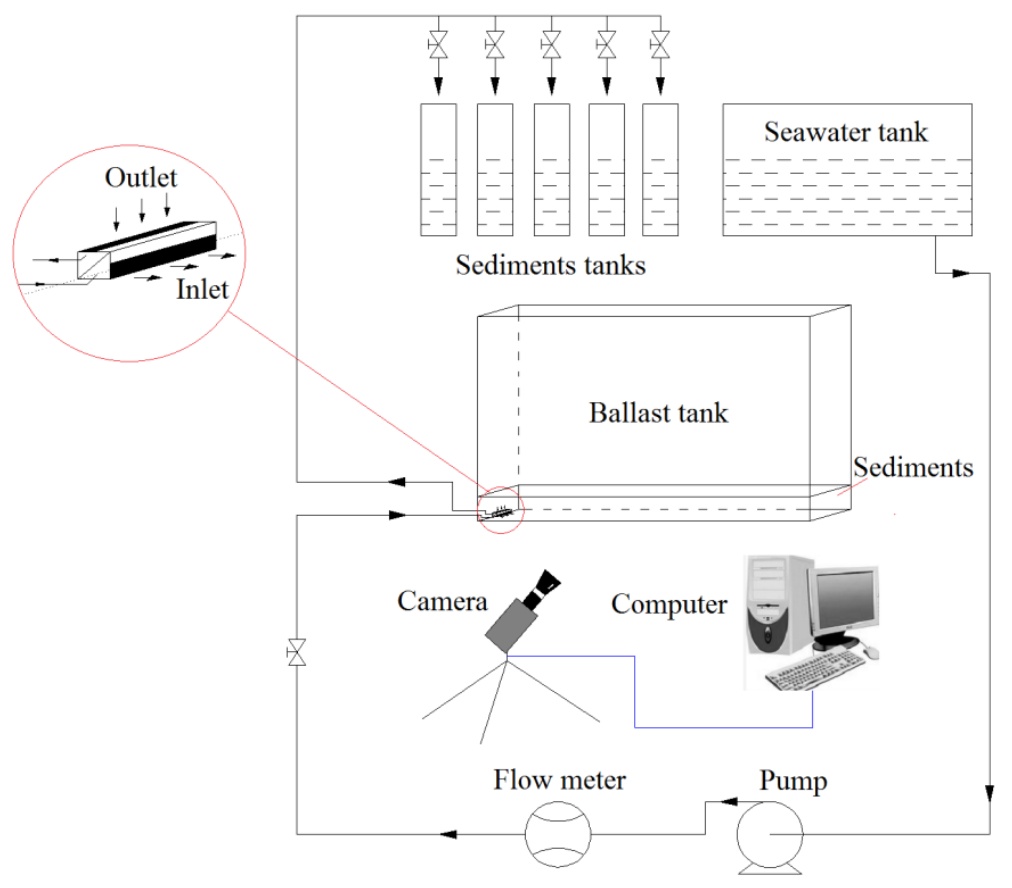

Figure 5 Experimental system

The real-time measurement of the sediments proportion that remains in the ballast 237 tank is difficult. A. Tamburini [33] provided a method of quantifying the sediments proportion in the entire tank. By introducing an impeller and measuring the density caused pressure variation, the percentage of suspended solids can be calculated. 
However, the impact of stirring process on the pressure of tank bottom is neglected in this method, which leads to a low precision in the measurement.

In this study, the mean sediments proportion in the ballast tank is calculated based on the weight of remained sediments in the ballast tank, which is ultimately measured by

244 the weight of sediments in the sediments tanks. The removed sediments are first 245 collected in the sediments tanks, and then weighted by oven drying method: after 246 being dried in the oven for 12 hours, the sediments are cooled to ambient temperature 247 in the dryer and weighted by an analytical balance. It is noted that a test consists of 3 248 replicates to arrive at the final result.

\section{Table 1 Parameters of instruments}

Analytical balance

Flowmeter
$0 \sim 0.2 \mathrm{~kg}, \pm 0.05 \%$

$0.10 \sim 10 \mathrm{~m}^{3} / \mathrm{h}, \pm 1.5 \%$

250

\subsection{Experimental plan}

$257 \quad F r=\frac{u}{\sqrt{g l}}$

258 Where, $u$ is the characteristic velocity of the flow, $l$ is the characteristic length scale 259 of the flow. 
Based on the similarity principle, the velocity scale and time scale for the

261

262

263

264

265

266

267

268

269

270

271

272

\begin{tabular}{ccc}
\hline Experimental conditions & Inlet velocity $\mathrm{m} / \mathrm{s}$ & Flow rate in pump L/s \\
\hline Test 1 & 1.58 & 0.0158 \\
Test 2 & 3.16 & 0.0316 \\
Test 3 & 4.74 & 0.0474 \\
Test 4 & 6.32 & 0.0632
\end{tabular}

experimental model can be determined as follows:

$u_{r}=T_{r}=\sqrt{l_{r}}$

Where, $l_{r}$ is the geometric scale of the experimental model, fixed at 1:10.

In the tests, the thickness of accumulated sediments on the tank bottom is $2 \mathrm{~mm}$ and the initial sediments volume fraction is made at $60 \%$. The bulk density of sediments is made at $1500 \mathrm{~kg} / \mathrm{m}^{3}$ and the measured median particle diameter is $11.64 \mu \mathrm{m}$. According to the calculation, the initial weight of the accumulated sediments on the tank bottom is $328.86 \mathrm{~g}$. Before conducting the experiments, these sediments are first fully suspended in the entire tank and then deposited in the tank, this process is to make sure they are uniformly distributed after settling down on the bottom.

The experimental plan is listed in Table 2.

\section{Table 2 Experimental plan}

(20)

\section{Results and discussions}

\section{5.1. Sediments distribution on the tank bottom}

276 Considering that the sediments discharged from the outlet of outflow-pipe are

277 separated in the hydrocyclone (with a relatively high separation efficiency of 98\%), 
thus, once the average proportion of the sediments in the ballast tank is less than $2 \%$,

279 the sediments in the ballast tank can be considered adequately removed. In the 280 simulation, 4 inlet velocities of $5 \mathrm{~m} / \mathrm{s}, 10 \mathrm{~m} / \mathrm{s}, 15 \mathrm{~m} / \mathrm{s}$ and $20 \mathrm{~m} / \mathrm{s}$ are assigned. The 281 isosurfaces of sediments proportion above $2 \%$ at 600 s are obtained and shown in 282 Figure 6.

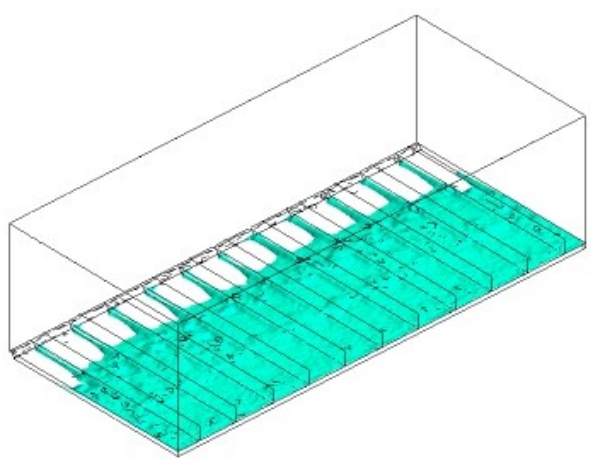

(a)

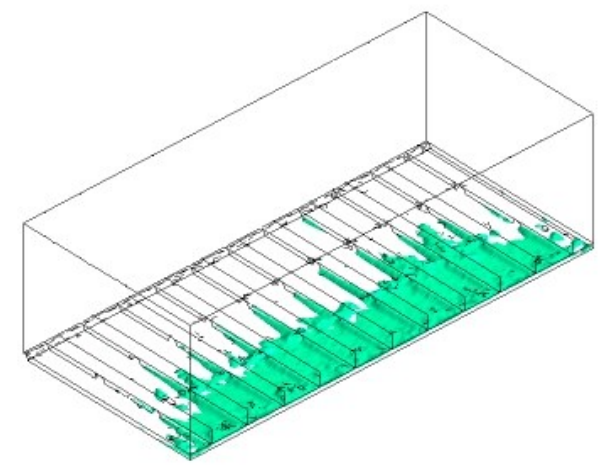

(c)

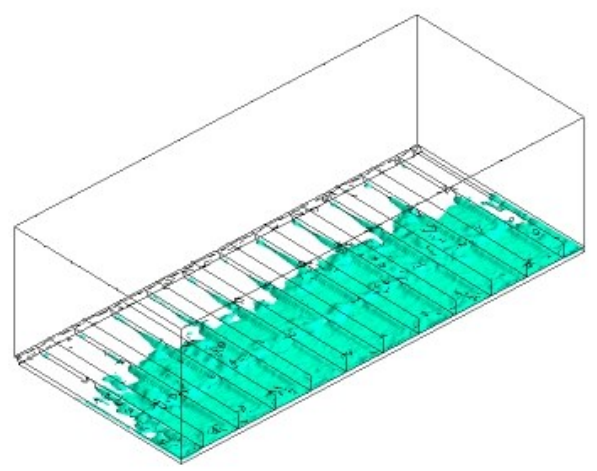

(b)

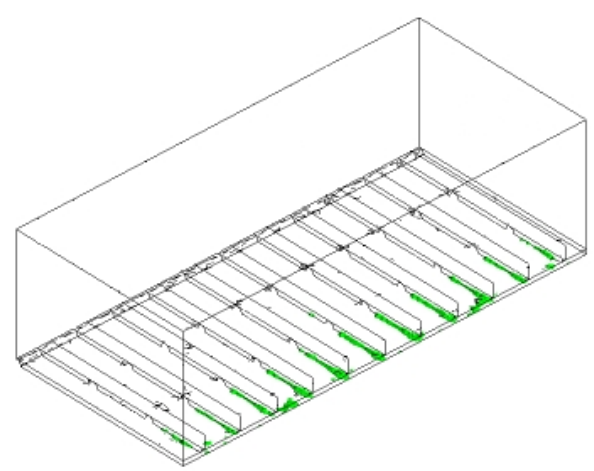

(d)

Figure 6 Isosurface of sediments proportion above $2 \%$ at 600 s with different velocity at $15 \mathrm{~m} / \mathrm{s}$; (d) inlet velocity at $20 \mathrm{~m} / \mathrm{s}$ that the sediments are suspended from the bottom left. With a higher inlet velocity, 
more sediment on the bottom is suspended at the same moment. Besides, since the jet holes are located in the midline of two bottom longitudinal plates, the sediments along this midline are first suspended. Also, it is found the sediments on the bottom right of the tank are latest suspended, thus the sediments proportion on the bottom right of the tank can be monitored, which indicates the suspension conditions of the ballast tank. Based on this observed results, the monitoring lines on the bottom right of the ballast tank are introduced in this study to evaluate the suspension conditions, and the results are discussed in the following section.

\subsection{Average sediments proportion in initial sediments layer}

The proportion of sediments remaining in the ballast tank over time is investigated in this study, and the results are obtained and shown in Figure 7 (a).

Generally, the simulation results show that the average sediments proportion in the ballast tank decreases over time, and higher inlet velocity leads to a more rapid decrease. To compare the simulation results with the experimental one, the time scale is taken into account, and these results show good match. Further, the decreasing speed is quantitatively analysed by introducing the $2 \%$ proportion line. Figure 7 (b) shows the results within a more narrow range in $\mathrm{x}$-axis. To reduce the sediments proportion to fewer than $2 \%$, less required time is needed with higher inlet velocity. For the simulation results, the required time with inlet velocity at $5 \mathrm{~m} / \mathrm{s}, 10 \mathrm{~m} / \mathrm{s}, 15 \mathrm{~m} / \mathrm{s}$, $20 \mathrm{~m} / \mathrm{s}$ are approximately $7200 \mathrm{~s}\left(\mathrm{~T}_{1}\right), 2300 \mathrm{~s}\left(\mathrm{~T}_{2}\right), 1250 \mathrm{~s}\left(\mathrm{~T}_{3}\right)$ and $790 \mathrm{~s}\left(\mathrm{~T}_{4}\right)$, respectively. In comparison, the experimental required time, after being processed on basis of the time scale, is obtained. The results show that the required time (considering the time scale) are approximately 6670s $\left(\sqrt{l_{r}} \mathrm{~T}_{1}{ }^{\prime}\right), 2190 \mathrm{~s}\left(\sqrt{l_{r}} \mathrm{~T}_{2}\right), 1180 \mathrm{~s}$ $\left(\sqrt{l_{r}} \mathrm{~T}_{3^{\prime}}\right)$ and 680s $\left(\sqrt{l_{r}} \mathrm{~T}_{4}{ }^{\prime}\right)$, respectively. 


$$
\begin{array}{llll}
\rightarrow 5 \mathrm{~m} / \mathrm{s} & \rightarrow 10 \mathrm{~m} / \mathrm{s} & -15 \mathrm{~m} / \mathrm{s} & \leftarrow 20 \mathrm{~m} / \mathrm{s} \\
\triangle \text { Test } 1 & \diamond \text { Test } 2 & \square \text { Test } 3 & \times \text { Test } 4
\end{array} \quad \longrightarrow \mathrm{VF}=2.0 \%
$$
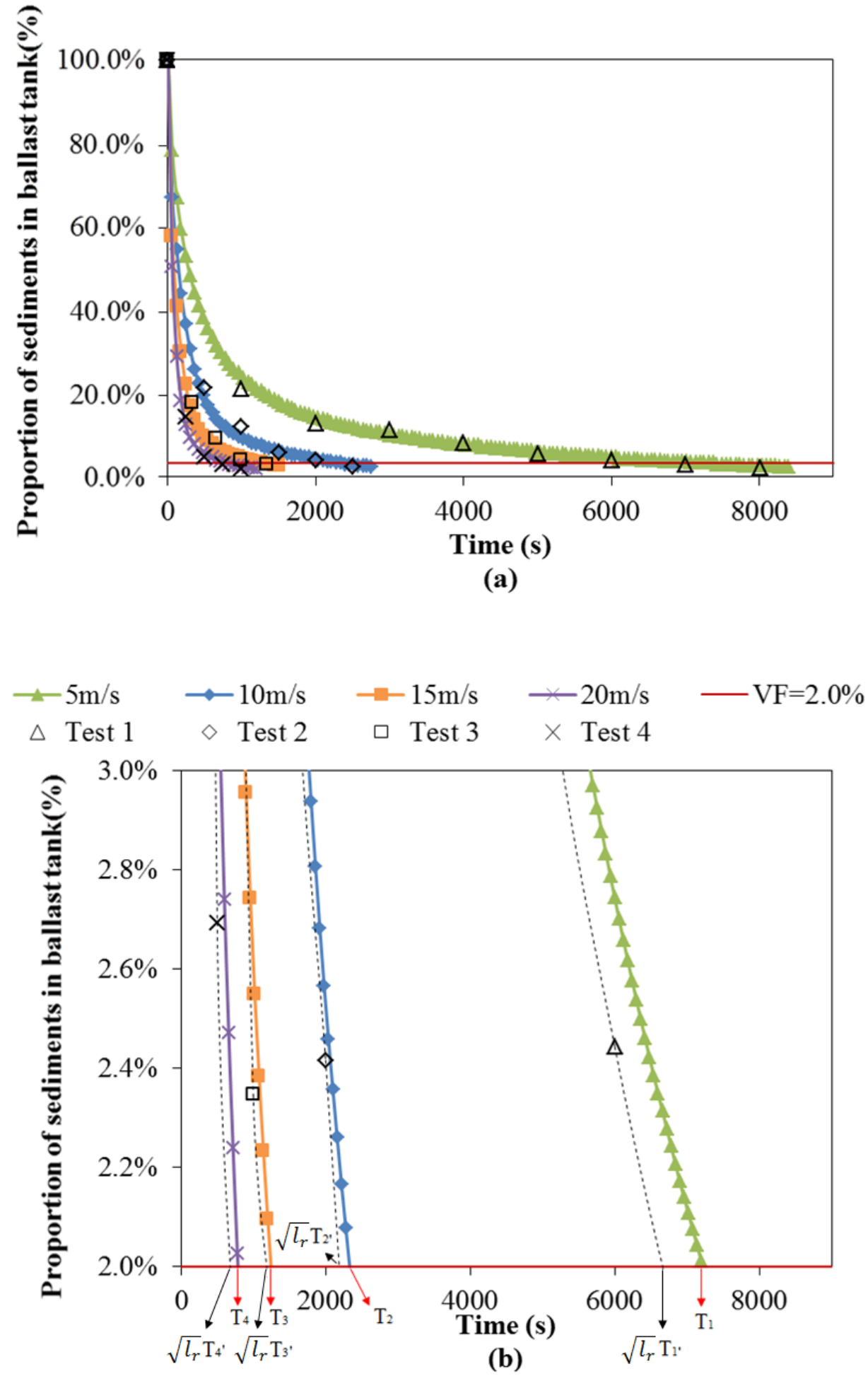


\subsection{Sediments distribution on the monitoring plane}

318 Figure 8 shows the simulation results of sediments distribution on the monitoring 319 plane as time varies. According to the simulation results in section 5.2, $T_{1}, T_{2}, T_{3}, T_{4}$ represent the required time of which the sediment are completely removed with 4

321 different inlet velocities. Further, a comparison study is made by the experiments,

322 shown in Figure 9. With the assistance of these studies, the flushing process inside the 323 ballast tank is observed. Generally, the sediments on the ballast tank bottom are first 324 stirred up by the water injected from the jet holes, and then be sucked into the exit 325 holes and get removed, remaining very small part of the sediments suspending in the 326 ballast tank.
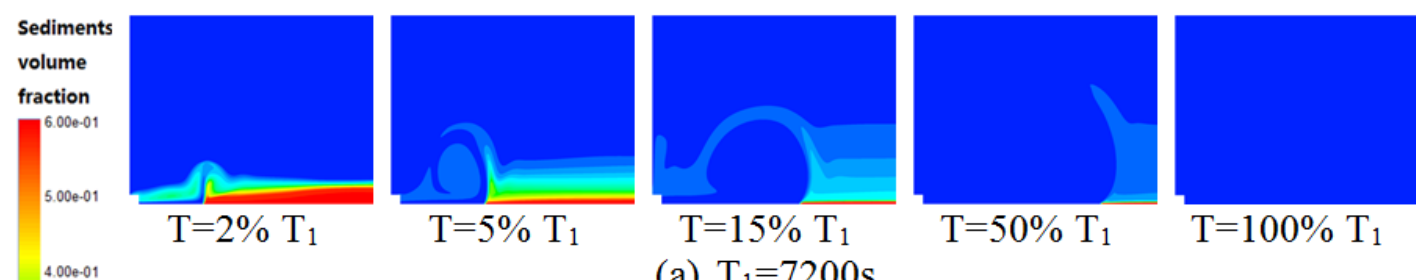

$\mathrm{T}=50 \% \mathrm{~T}_{1}$

$\mathrm{T}=100 \% \mathrm{~T}_{1}$
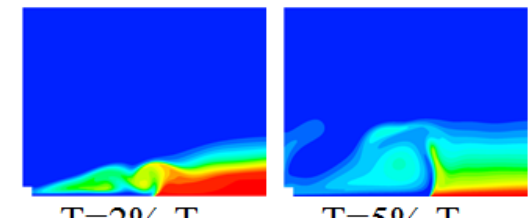

(a) $\mathrm{T}_{1}=7200 \mathrm{~s}$
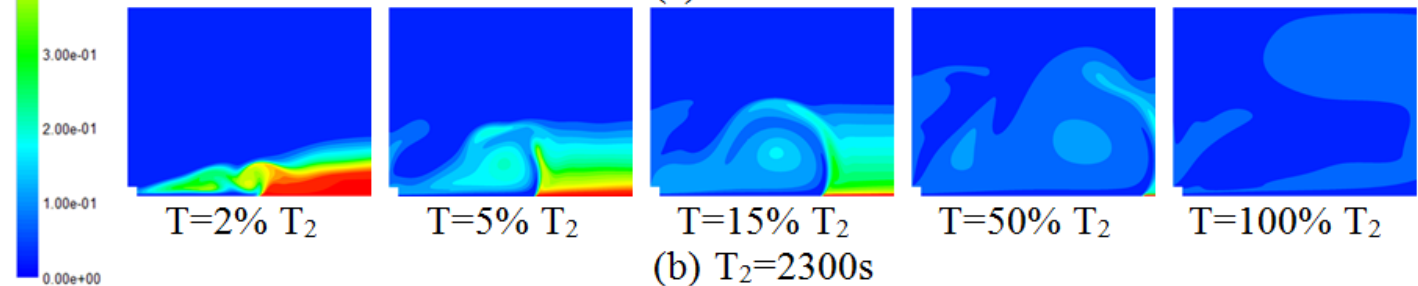

(b) $\mathrm{T}_{2}=2300 \mathrm{~s}$
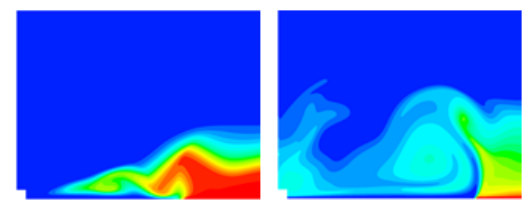

$\mathrm{T}=2 \% \mathrm{~T}_{3}$

$\mathrm{T}=5 \% \mathrm{~T}_{3}$

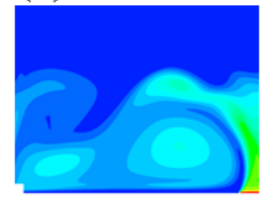

$\mathrm{T}=15 \% \mathrm{~T}_{3}$

$\mathrm{T}=50 \% \mathrm{~T}_{2}$

$\mathrm{T}=100 \% \mathrm{~T}_{2}$

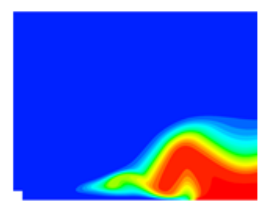

$\mathrm{T}=2 \% \mathrm{~T}_{4}$

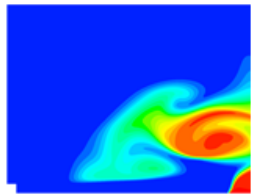

(c) $\mathrm{T}_{3}=1250 \mathrm{~s}$

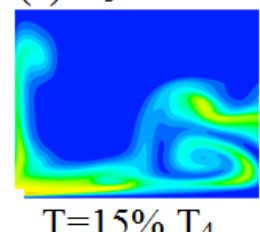

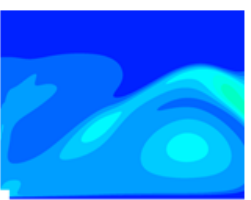

$\mathrm{T}=50 \% \mathrm{~T}_{3}$
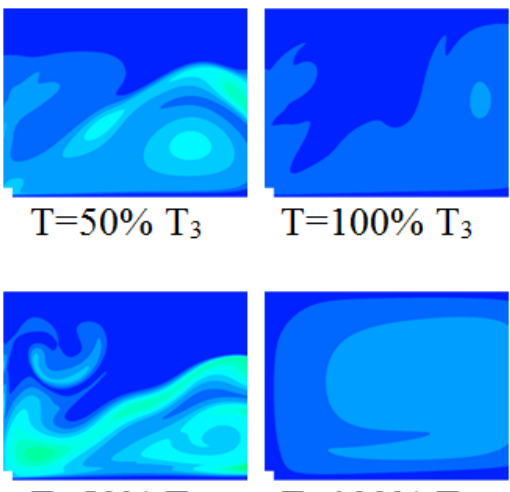

$\mathrm{T}=50 \% \mathrm{~T}_{4} \quad \mathrm{~T}=100 \% \mathrm{~T}_{4}$

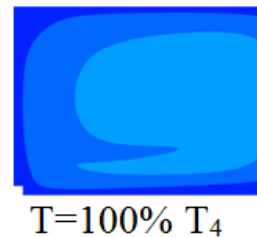

(d) $\mathrm{T}_{4}=790 \mathrm{~s}$ 
Figure 8 Simulation results of sediments distribution on the monitoring plane with different inlet velocity: (a) inlet velocity at $5 \mathrm{~m} / \mathrm{s}$; (b) inlet velocity at $10 \mathrm{~m} / \mathrm{s}$; (c) inlet
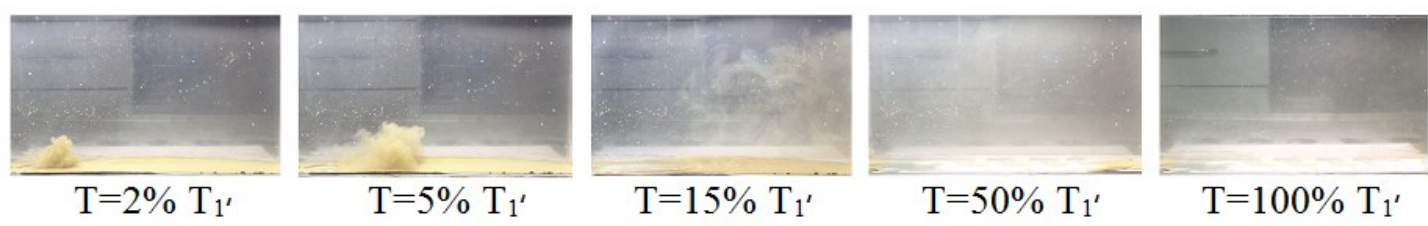

(a)
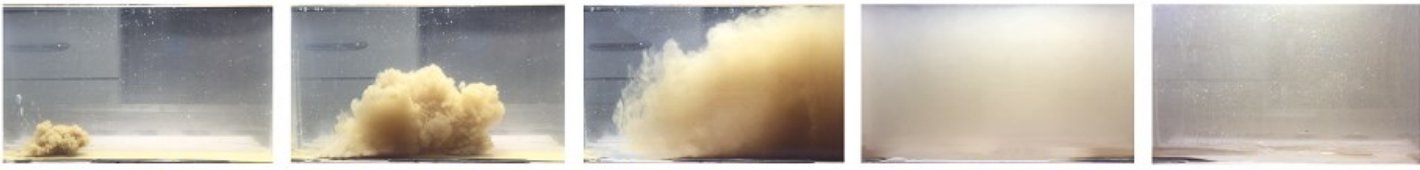

(b)
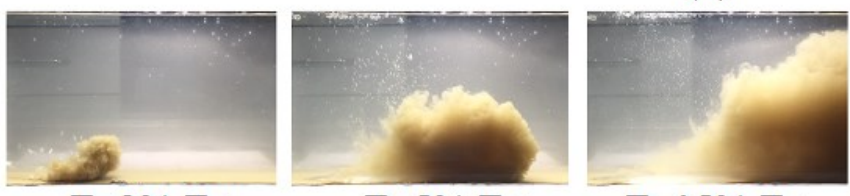

$\mathrm{T}=15 \% \mathrm{~T}_{3^{\prime}}$

$\mathrm{T}=50 \% \mathrm{~T}_{2}$

$\mathrm{T}=100 \% \mathrm{~T}_{2^{\prime}}$

(c)

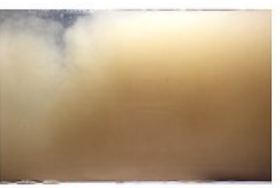

$\mathrm{T}=50 \% \mathrm{~T}^{\prime}$

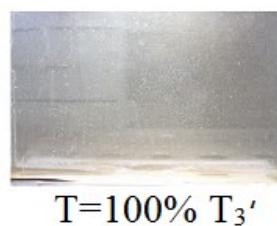

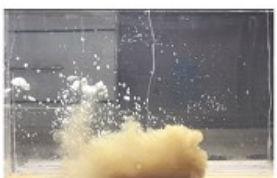

$\mathrm{T}=2 \% \mathrm{~T}_{4^{\prime}}$

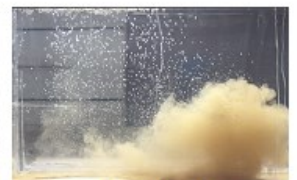

$\mathrm{T}=5 \% \mathrm{~T}_{4}{ }^{\prime}$

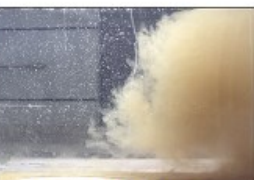

$\mathrm{T}=15 \% \mathrm{~T}_{4}$

(d)

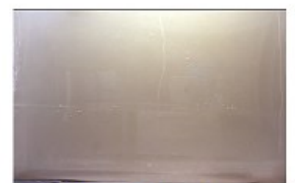

$\mathrm{T}=50 \% \mathrm{~T}_{4}{ }^{\prime}$

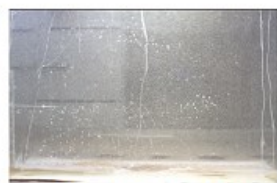

$\mathrm{T}=100 \% \mathrm{~T}_{4}^{\prime}$

Figure 9 Experimental results of sediments distribution with different inlet velocity: (a) inlet velocity at $1.58 \mathrm{~m} / \mathrm{s}$; (b) inlet velocity at $3.16 \mathrm{~m} / \mathrm{s}$; (c) inlet velocity at $4.74 \mathrm{~m} / \mathrm{s}$;

According to these results, the inlet velocity greatly affects the suspending of sediments. With a lower inlet velocity, the sediments are gradually stirred up from bottom left to right, while this process occurs drastically when the inlet velocity is at a higher level. The removing process is observed from this figure. The bottom sediments are suspended with the injected water, and then get discharged from the exit holes. Also, lower inlet velocity means that much longer time is needed to fully 
suspend the bottom sediments. As is shown in Figure 8 (a), it takes more than 7000s

342 to fully remove the sediments with the inlet velocity at $5 \mathrm{~m} / \mathrm{s}$. Compared with this,

343 Figure 8 (d) shows that only approximately 900 s is needed to get a similar result with 344 the inlet velocity at $20 \mathrm{~m} / \mathrm{s}$. And similar phenomenon can be observed in the 345 experimental study.

\subsection{Average sediments volume fraction on the monitoring lines}

347 According to the initial conditions made in this simulation, the average sediments

348 volume fractions on each monitoring line are obtained, shown in Figure 10. Similarly, 349 the flow time is also selected as the variable parameter. Noting that when $\mathrm{t}=0 \mathrm{~s}$, the 350 corresponding sediments volume fraction on different monitoring lines are at different 351 values. As it was assigned in the initial conditions, for monitoring lines of $\mathrm{z}=0 \mathrm{~mm}$, $35210 \mathrm{~mm}$ and $20 \mathrm{~mm}$, the sediments volume fraction are all $60 \%$; while for monitoring 353 lines of $\mathrm{z}=30 \mathrm{~mm}$ and $40 \mathrm{~mm}$, this value are both at 0 . As time varies, it is found that 354 the sediments volume fraction draw curves differently. On the monitoring lines of $355 \mathrm{z}=0 \mathrm{~mm}, 10 \mathrm{~mm}$ and $20 \mathrm{~mm}$, where these lines are within the initial sediments layer, the 356 sediments volume fractions decrease rapidly from $60 \%$ to less than $20 \%$ over time, 357 and then they draw slightly decrease to 0 . On the monitoring lines of $z=30 \mathrm{~mm}$ and $35840 \mathrm{~mm}$, it is noted that the sediments volume fractions first climb up to $10-30 \%$ before 359 decrease gradually to 0 . This is attributed to the following reason: as the sediments 360 near the jet holes are stirred up, they are entrained by the injected water and 361 accumulated on the right bottom of the ballast tank firstly, and then these sediments 362 are removed slightly over time. This phenomenon has also been detected in Figure 8 363 and Figure 9. 
With different velocity at inflow-pipe inlet, the average sediments volume fractions of 365 ballast water at the same moment are also quite different. When $t=1000 \mathrm{~s}$, the 366 sediments volume fractions on the tank bottom $(\mathrm{z}=0 \mathrm{~mm})$ are obtained. With inlet 367 velocity at $5 \mathrm{~m} / \mathrm{s}, 10 \mathrm{~m} / \mathrm{s}, 15 \mathrm{~m} / \mathrm{s}$ and $20 \mathrm{~m} / \mathrm{s}$, this parameter decreases to approximately $36822.3 \%, 8.6 \%, 2.5 \%$ and $1.3 \%$, respectively. This indicates that higher inlet velocity results in a better sediments suspension on the bottom. Besides of the tank bottom 370 monitoring line, other monitoring lines are all found decrease drastically as the inlet 371 velocity increases. Thus it is an effective method of removing the sediments by 372 increasing the inlet velocity of inflow-pipe.

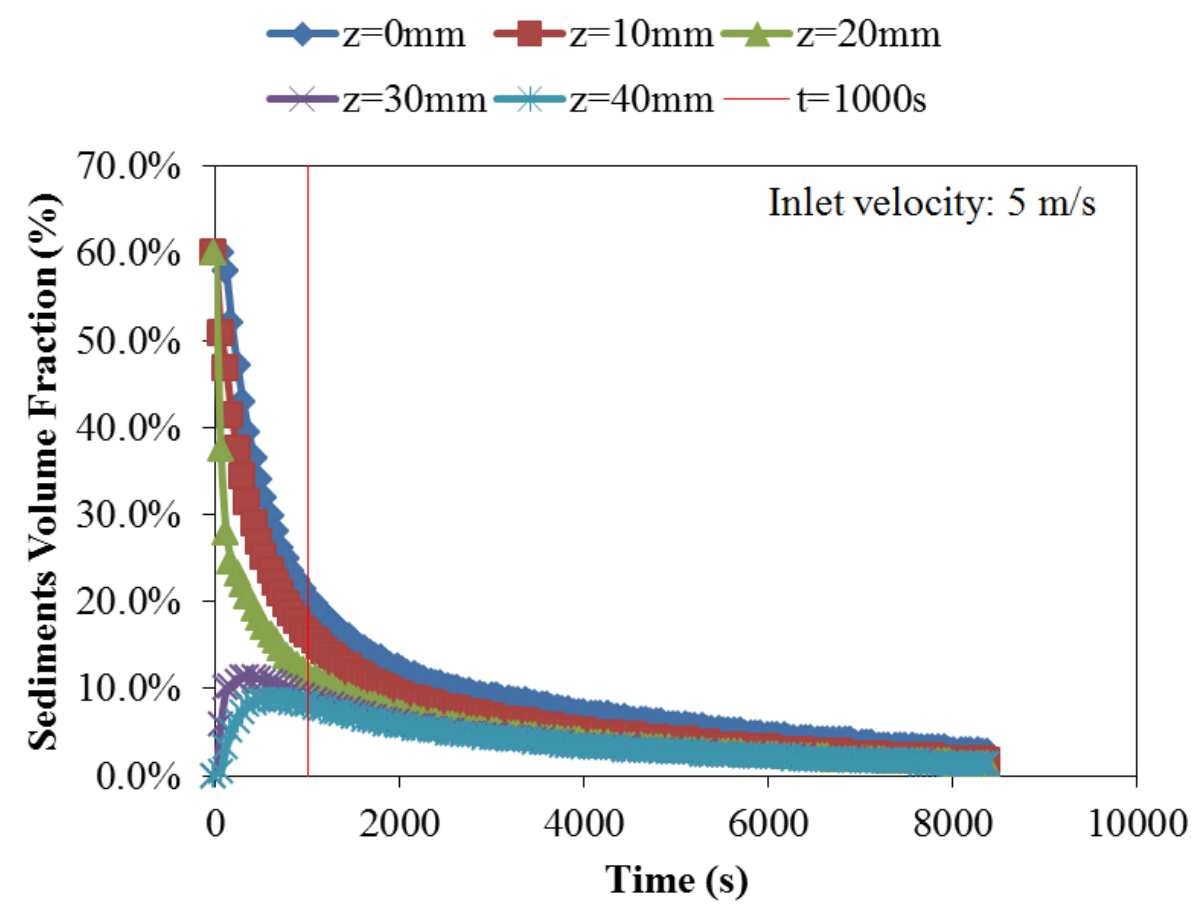

(a) 


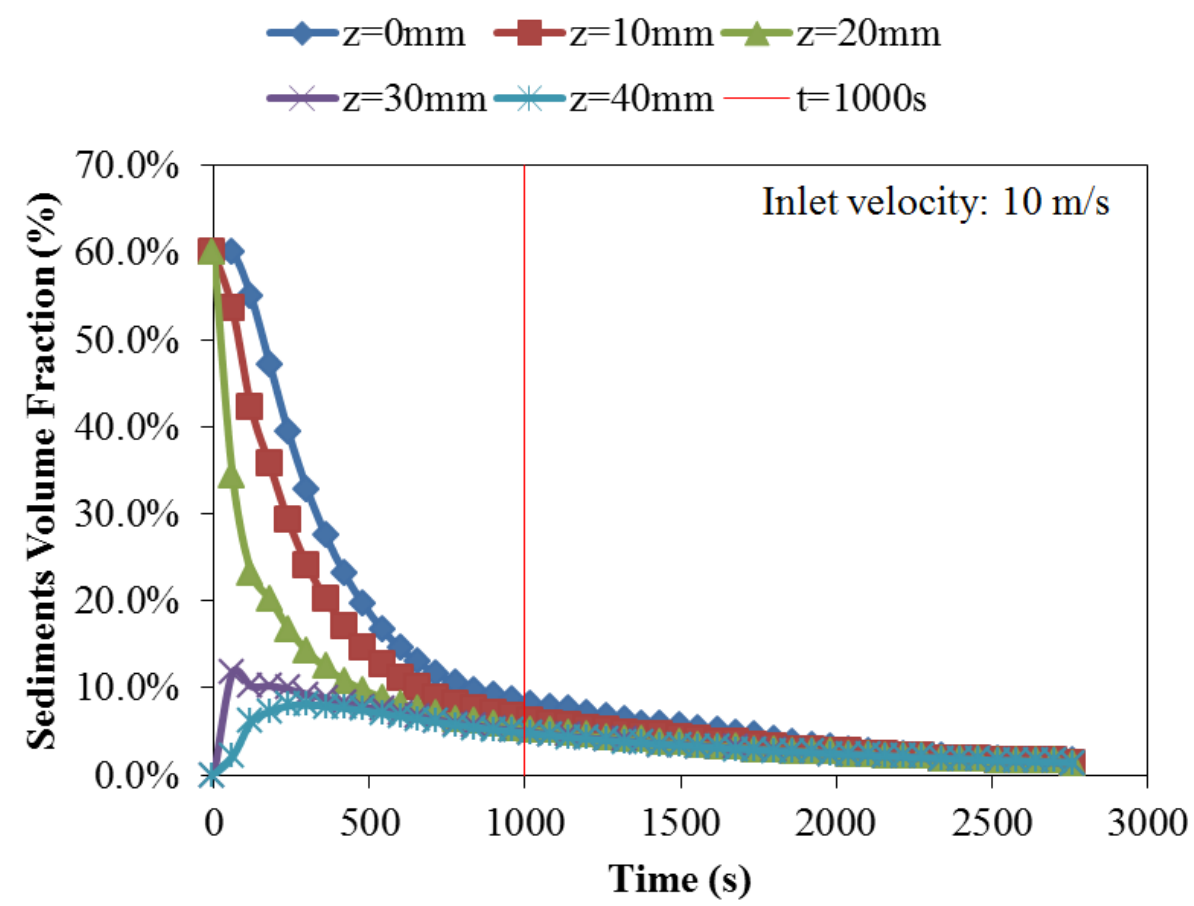

(b)

374

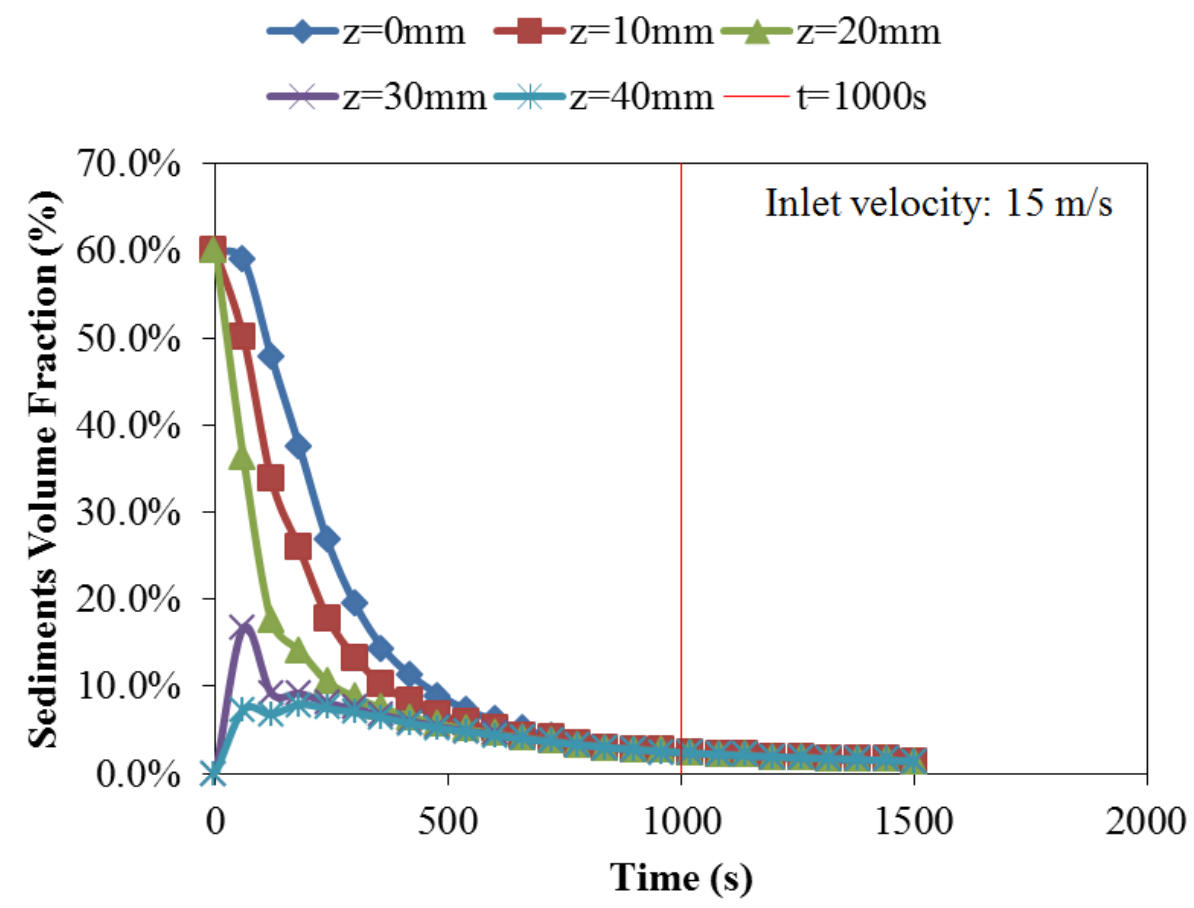

(c) 


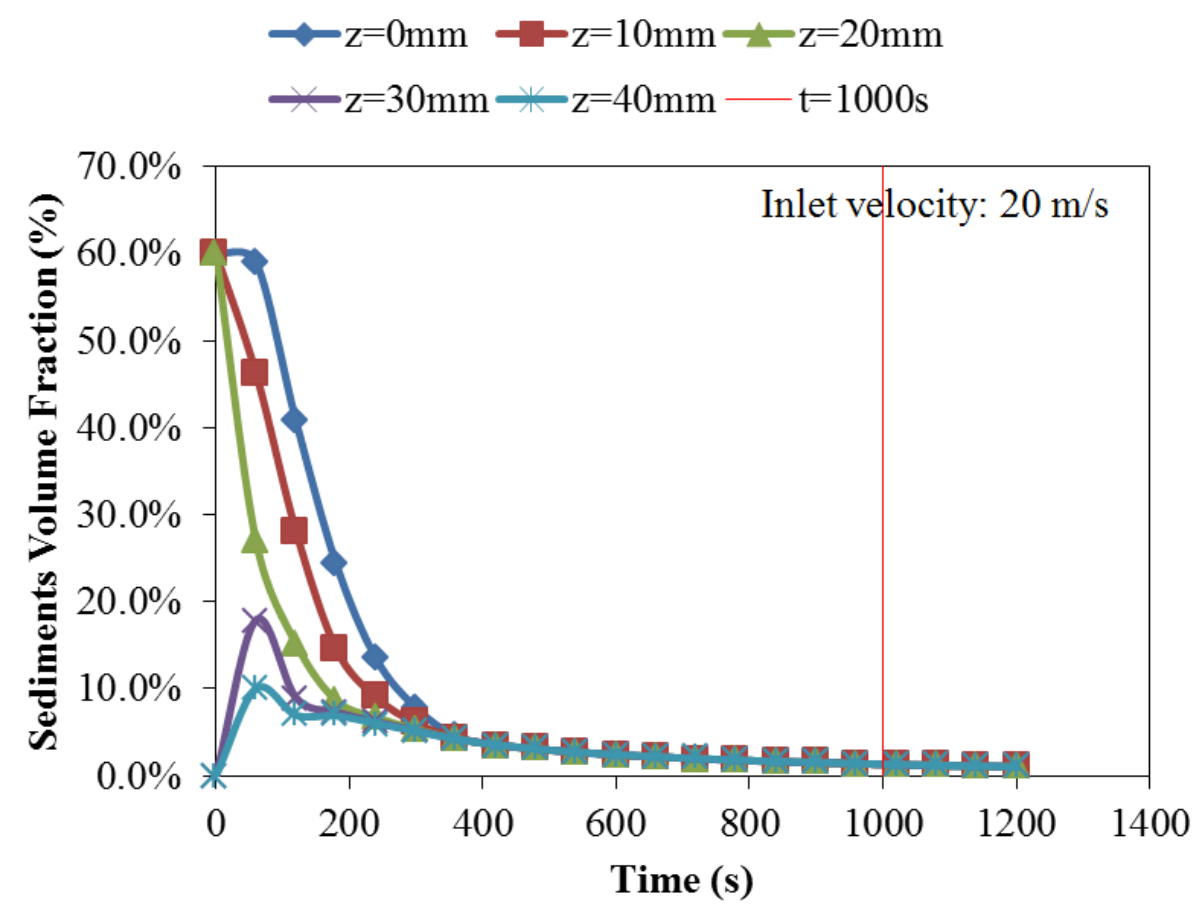

(d)

Figure 10 average sediments volume fraction on the monitoring lines

378 5.5. Energy consumption of the pump at different inlet velocities as the sediments proportion in initial sediments layer varies

380 Since the circulating pump is the only energy consumption component in this system, 381 its energy consumption is the key parameter to evaluate the performance of this system. Generally, the energy consumption of the circulating pump is defined as:

$383 W_{P}=\left(E_{b w}+W_{\text {loss }}\right) \eta_{P}$

385 $P_{0}+\frac{1}{2} \rho_{m} u_{0}=P_{1}+\frac{1}{2} \rho_{m} u_{1}$ 
387 Where, $E_{b w}$ is the total energy of the fluid in the ballast tank, $P_{0}$ and $P_{1}$ are the inlet 388 pressure of the inflow-pipe and the outlet pressure of the outflow-pipe, respectively, $389 W_{\text {loss }}$ is the energy losses of the pipe, $\rho_{m}$ is the density of sediments-seawater mixture, $390 \Delta P_{\text {loss }}$ is the pressure losses along the pipe.

$\leftarrow 5 \mathrm{~m} / \mathrm{s} \longrightarrow 10 \mathrm{~m} / \mathrm{s} \rightarrow-15 \mathrm{~m} / \mathrm{s} \rightarrow 20 \mathrm{~m} / \mathrm{s} \quad \mathrm{VF}=2.0 \%$

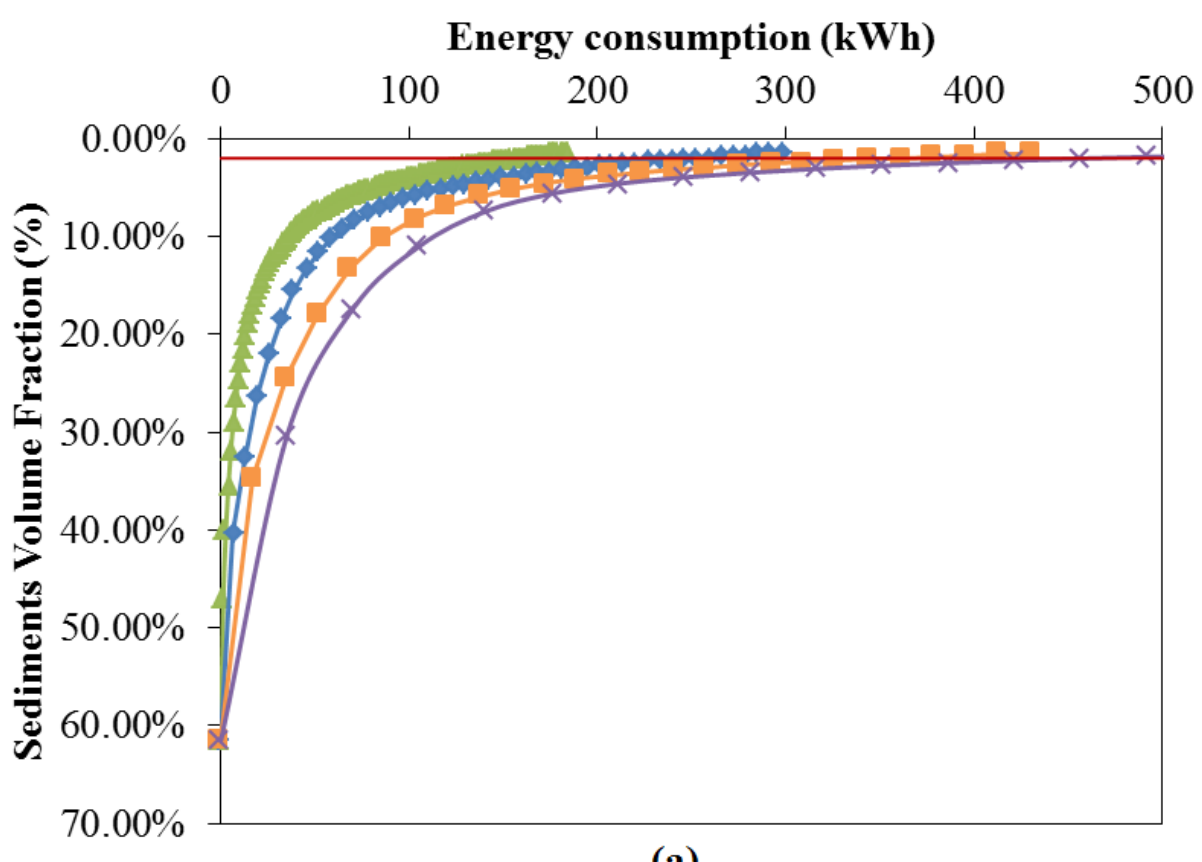



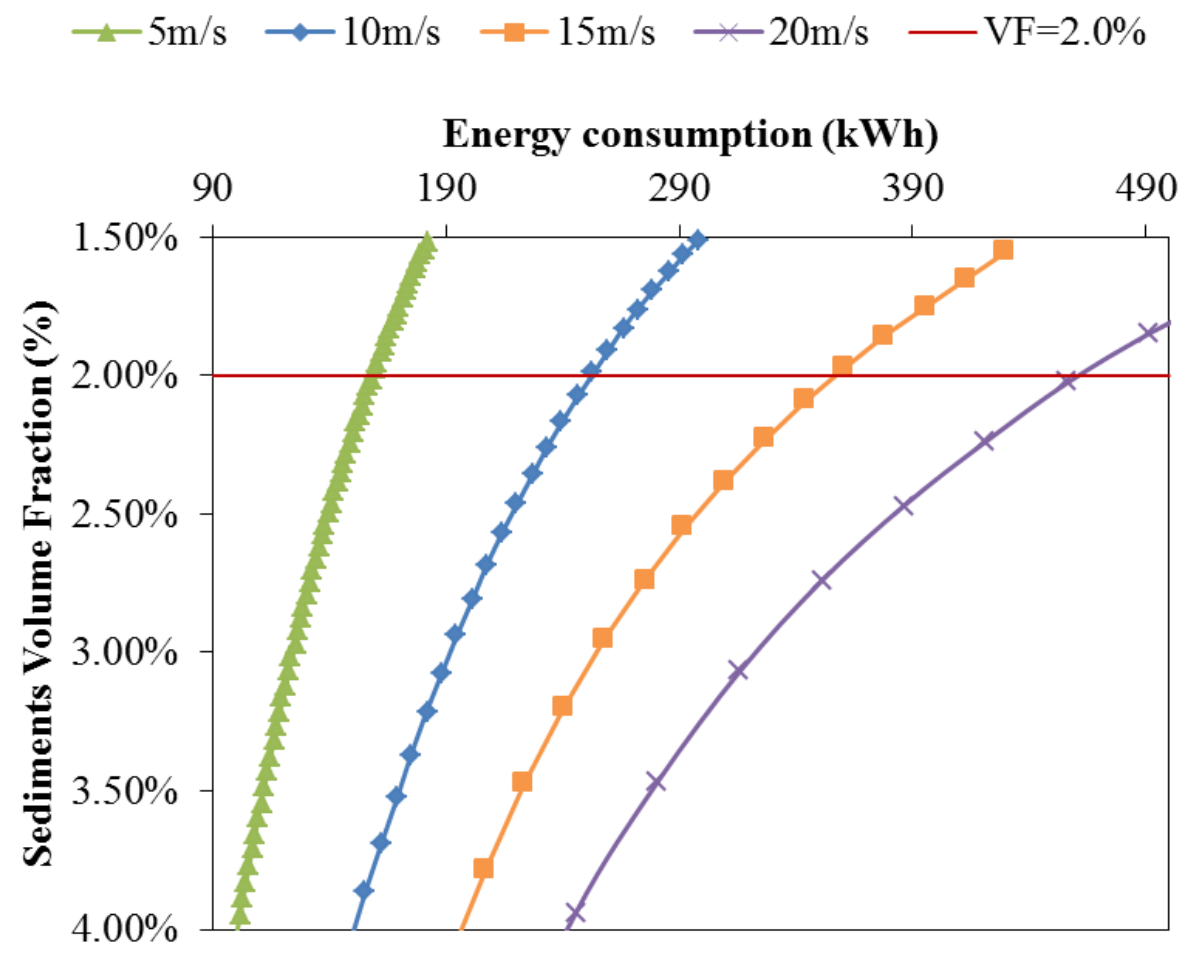

392

Figure 11 Energy consumption of circulating pump at different inlet velocities

According to Eq. (19-22), the energy consumption of the circulating pump is calculated and the results are shown in Figure 11. Generally, in order to get the same suspension effect, higher inlet velocity means higher energy consumption in circulating pump. The $2 \%$ sediments proportion line is also selected in this section as the critical line, which represents the fully suspension of the sediments. To reach this sediments proportion level, it is found that the energy consumption of $460 \mathrm{kWh}$ is required for inlet velocity at $20 \mathrm{~m} / \mathrm{s}$. And this is followed by $356 \mathrm{kWh}, 252 \mathrm{kWh}$ and $156 \mathrm{kWh}$ for inlet velocity at $15 \mathrm{~m} / \mathrm{s}, 10 \mathrm{~m} / \mathrm{s}$ and $5 \mathrm{~m} / \mathrm{s}$. These results are reasonable, for higher inlet velocity in inflow-pipe leads to higher kinetic energy of inject water and higher resistance losses in pipes and tank. Therefore, higher inlet velocity can increase the sediments removing speed; nevertheless, it can also result in higher energy consumption in circulating pump. 


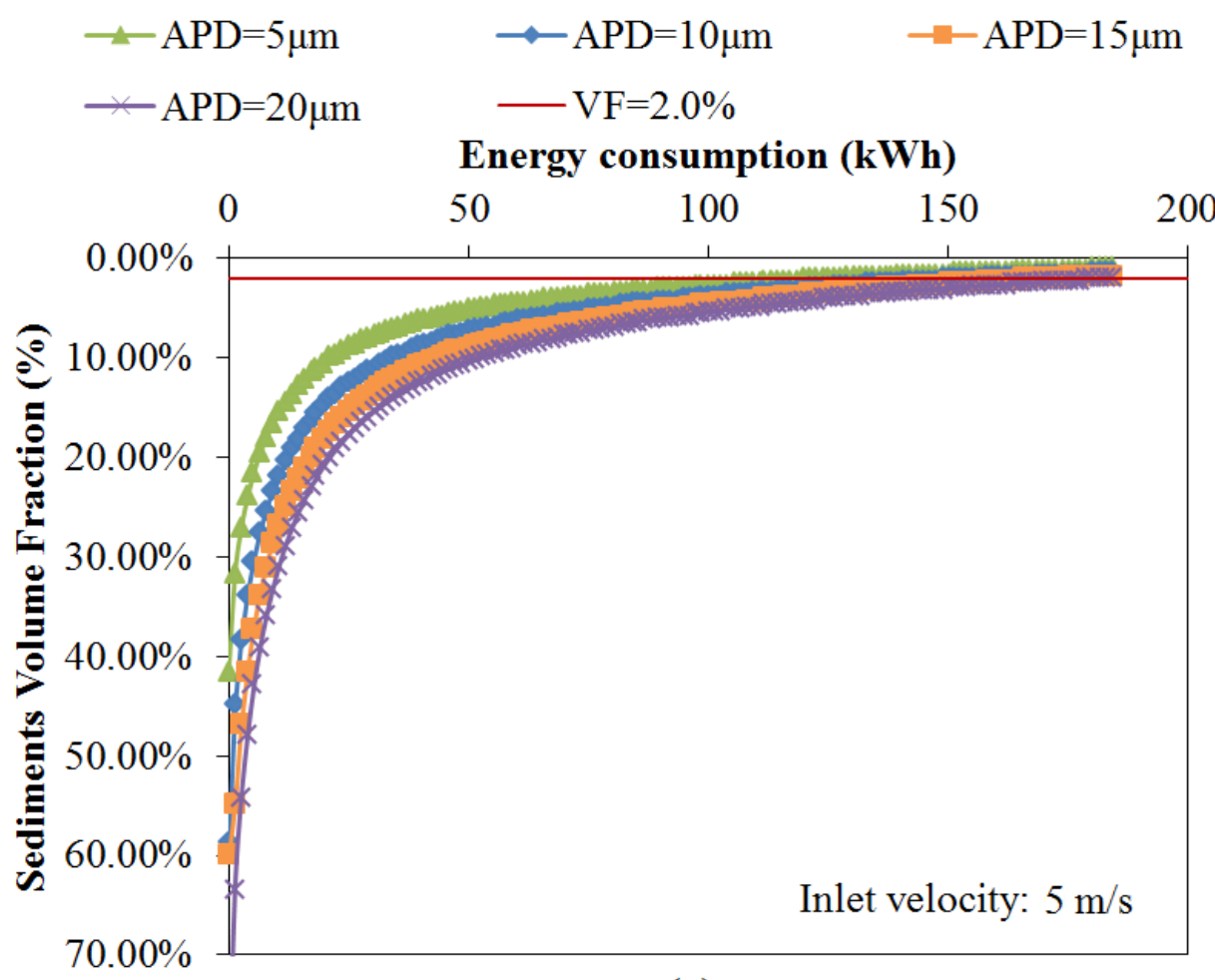

406

(a)

$$
\begin{aligned}
& \rightarrow \mathrm{APD}=5 \mu \mathrm{m} \quad \longrightarrow \mathrm{APD}=10 \mu \mathrm{m} \quad \rightarrow \mathrm{APD}=15 \mu \mathrm{m} \\
& \leftarrow \mathrm{APD}=20 \mu \mathrm{m} \quad-\mathrm{VF}=2.0 \%
\end{aligned}
$$

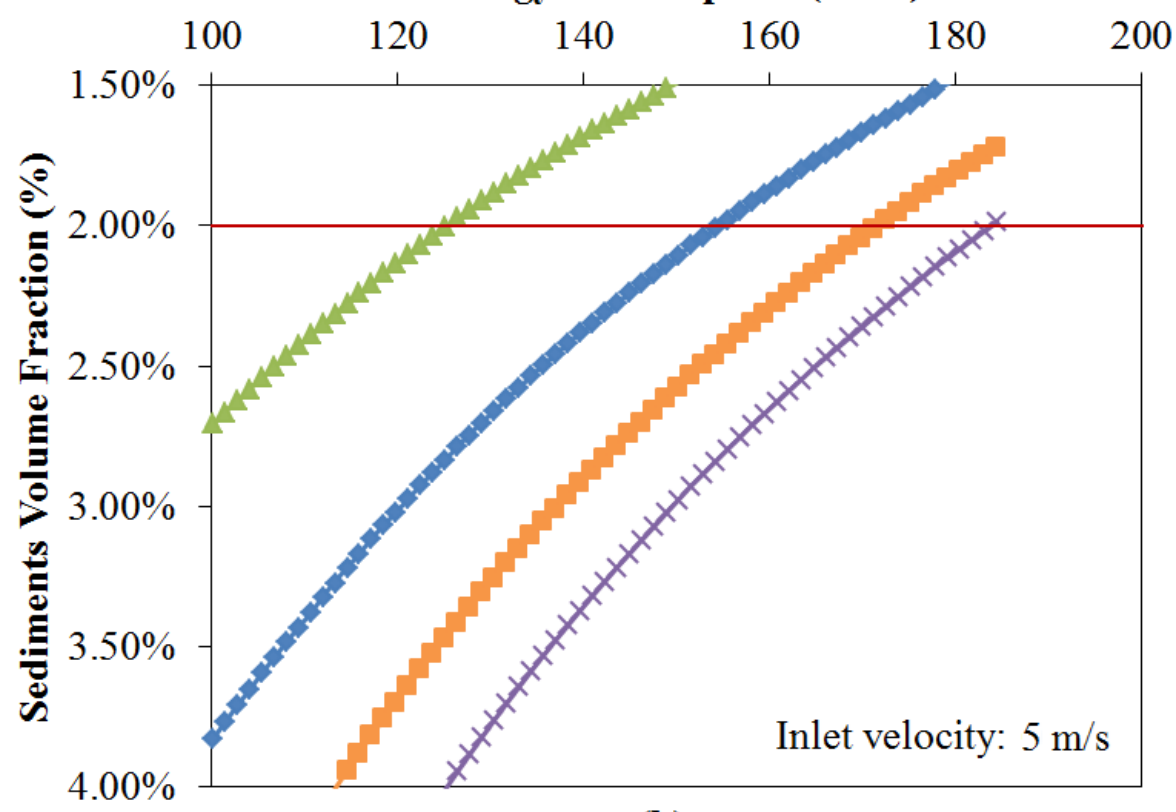

407

(b) 
409 Further, the effect of particle size on the performance of ballast water flushing system

410 is investigated. The energy consumption of the circulating pump with 4 different

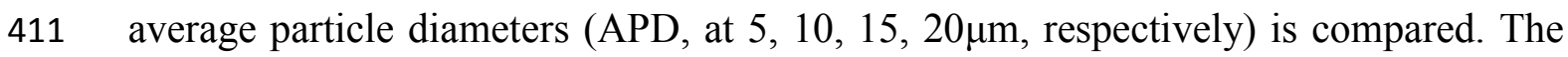

412 inlet velocity of this system is chosen at $5 \mathrm{~m} / \mathrm{s}$. The simulation results are shown in

413 Figure 12. The result indicates that more energy will be consumed with larger particle

414 size. To reach the $2 \%$ sediments proportion level, it is found the energy consumption

415 of $125 \mathrm{kWh}$ is required for $\mathrm{APD}$ at $5 \mu \mathrm{m}$. This is follower by $154 \mathrm{kWh}, 171 \mathrm{kWh}$, $416184 \mathrm{kWh}$ for APD at 10,15 and $20 \mu \mathrm{m}$.

\section{Conclusions}

This study proposed a ballast water flushing system for ballast sediments removing purpose. By circulating the ballast water, the deposited sediments on the bottom of the ballast tank can be stirred up and separated in the hydrocyclone. With the assistance of this system, no modification is needed for the tank structure. Also, the evacuating of ballast water is needless during the sediments removing process. With the flushing system, the unfiltered sediments along with the regrown organisms can be removed when needed. This proposed flushing system could be considered as an alternative technique for ballast water management. In this study, the simulation model for this flushing system is made. Moreover, a 1:10 scaled experimental setup is established based on the similarity principle. Both simulation and experimental investigation are conducted to reveal the performance of this flushing system. Based on the analysis 430 made in this study, conclusions can be drawn as follows: higher magnitude of inlet velocity, the required time for suspending sediments on 
the bottom of the tank can be greatly decreased.

434

435

437

- The sediments on the bottom of the ballast tank first accumulate at the far end, with the sediments volume fraction climbs up to $10-30 \%$. Then these sediments get removed over time and the sediments volume fraction decreases gradually to 0.

- Higher inlet velocity leads to a more rapid decrease of average sediments proportion in the ballast tank over time. For the simulation results, the required time for totally removing of sediments is approximately 7200s (with inlet velocity at $5 \mathrm{~m} / \mathrm{s}), 2300 \mathrm{~s}(10 \mathrm{~m} / \mathrm{s}), 1250 \mathrm{~s}(15 \mathrm{~m} / \mathrm{s})$ and $790 \mathrm{~s}(20 \mathrm{~m} / \mathrm{s})$, respectively. Similar results are obtained from the experiments.

- To get the same suspension effect, higher inlet velocity means much higher energy consumption in circulating pump. The energy consumption of $460 \mathrm{kWh}$ is required (with inlet velocity at $20 \mathrm{~m} / \mathrm{s}$ ), followed by $356 \mathrm{kWh}, 252 \mathrm{kWh}$ and $156 \mathrm{kWh}$ with inlet velocity at $15 \mathrm{~m} / \mathrm{s}, 10 \mathrm{~m} / \mathrm{s}$ and $5 \mathrm{~m} / \mathrm{s}$, respectively. Besides, more energy will be consumed with larger particle size.

\section{Acknowledgements}

The authors acknowledge the support provided by the National Natural Science Foundation of China (NO. 51679225) and the National Natural Science Foundation of China (NO. 51276174).

\section{References}

[1] A. Djoghlaf, Convention on Biological Diversity (CBD), 2008.

[2] D.R. Scriven, C. DiBacco, A. Locke, T.W. Therriault, Ballast water management in Canada: A historical perspective and implications for the future, Marine Policy, 59 (2015) 121-133. 
[3] J.L. Molnar, R.L. Gamboa, C. Revenga, M.D. Spalding, Assessing the global threat of invasive species to marine biodiversity, Frontiers in Ecology \& the Environment, 6 (2008) 485-492.

[4] T.A. Shiganova, Invasion of the Black Sea by the ctenophore Mnemiopsis leidyi and recent changes in pelagic community structure, Fisheries Oceanography, 7 (1998) 305-310.

[5] F. Pearce, How the Soviet seas were lost, New Scientist, (1995).

[6] M.A. Doblin, F.C. Dobbs, Setting a size-exclusion limit to remove toxic dinoflagellate cysts from ships' ballast water, Marine Pollution Bulletin, 52 (2006) 259-263.

[7] M. Učur, International convention for the control and management of ships' ballast water and sediments (imo, 2004), Naše more, Znanstveno-stručni časopis za more i pomorstvo, 58 (2011) 124-131.

[8] J. Čulin, B. Mustać, Environmental risks associated with ballast water management systems that create disinfection by-products (DBPs), Ocean \& Coastal Management, 105 (2015) 100-105.

[9] B. Werschkun, S. Banerji, O.C. Basurko, M. David, F. Fuhr, S. Gollasch, T. Grummt, M. Haarich, A.N. Jha, S. Kacan, Emerging risks from ballast water treatment: The run-up to the International Ballast Water Management Convention, Chemosphere, 112 (2014) 256-266. [10] A.N. Cohen, F.C. Dobbs, Failure of the public health testing program for ballast water treatment systems, Marine Pollution Bulletin, 91 (2015) 29-34.

[11] N. Dobroski, C. Brown, R. Nedelcheva, C. Scianni, J. Thompson, 2015 Biennial Report on the California Marine Invasive Species Program, (2015).

[12] F.L. Darby, Stemming the tide: Controlling introductions of nonindigenous species by ships' ballast water : By National Research Council. National Academy Press, 1996. ISBN 0309-05537-7, US\$39.95, Shanghai Coustruction Science \& Technology, 35 (1997) 45-46.

[13] L. Maglić, D. Zec, V. Frančić, Ballast water sediment elemental analysis, Marine Pollution Bulletin, 30 (2016) 68-72.

[14] A. Kremp, D.M. Anderson, Factors regulating germination of resting cysts of the spring bloom dinoflagellate Scrippsiella hangoei from the northern Baltic Sea, Journal of Plankton Research, 22 (2000) 1311-1327(1317).

[15] S. Itakura, M. Yamaguchi, Germination characteristics of naturally occurring cysts of Alexandrium tamarense (Dinophyceae) in Hiroshima Bay, Inland Sea of Japan, Phycologia, 40 (2001) 263-267.

[16] R.I. Figueroa, I. Bravo, E. Garcés, I. Ramilo, NUCLEAR FEATURES AND EFFECT OF NUTRIENTS ON GYMNODINIUM CATENATUM (DINOPHYCEAE) SEXUAL STAGES, Journal of Phycology, 42 (2006) 67-77.

[17] J.P. Hamer, T.A. McCollin, I.A.N. Lucas, Dinoflagellate Cysts in Ballast Tank Sediments: Between Tank Variability, Marine Pollution Bulletin, 40 (2000) 731-733.

[18] G. Prange, Ship Ballast Tank Sediment Reduction Methods, Naval Engineers Journal, 125 (2013) 127-134.

[19] I. Eames, M. Landeryou, A. Greig, J. Snellings, Continuous flushing of contaminants from ballast water tanks, Marine Pollution Bulletin, 56 (2008) 250-260.

[20] I.A.o.C.S. (IACS), Guidelines for Coating Maintenance \& Repairs for Ballast Tanks and Combined Cargo/Ballast Tanks on Tankers, in: IACS Recommendation 87, 2006.

[21] M. Stipaničev, F. Turcu, L. Esnault, E.W. Schweitzer, R. Kilian, R. Basseguy, Corrosion behavior of carbon steel in presence of sulfate-reducing bacteria in seawater environment, Electrochimica Acta, 113 (2013) 390-406.

[22] Y. Lee, I. Sim, Y. Kim, J. Jung, J. Park, T. Jang, S. Kwon, Experimental study on sloshing for large LNGC design, in: The Fifteenth International Offshore and Polar Engineering Conference, International Society of Offshore and Polar Engineers, 2005.

[23] K. Pazouki, Inferential measurement and control of ballast water treatment system, (2012). 
[24] M. Shahrokhi, F. Rostami, M.M. Said, S. Syafalni, Numerical Modeling of the Effect of the Baffle Location on the Flow Field, Sediment Concentration and Efficiency of the Rectangular Primary Sedimentation Tanks, World Applied Sciences Journal, 15 (2011) 12961309.

[25] B. Liu, J. Ma, L. Luo, Y. Bai, S. Wang, J. Zhang, Two-dimensional LDV measurement, modeling, and optimal design of rectangular primary settling tanks, Journal of Environmental Engineering, 136 (2009) 501-507.

[26] R. Tarpagkou, A. Pantokratoras, CFD methodology for sedimentation tanks: The effect of secondary phase on fluid phase using DPM coupled calculations, Applied Mathematical Modelling, 37 (2013) 3478-3494.

[27] A. Alvarado, S. Vedantam, P. Goethals, I. Nopens, A compartmental model to describe hydraulics in a full-scale waste stabilization pond, Water research, 46 (2012) 521-530. [28] A. Tamburini, A. Cipollina, G. Micale, A. Brucato, M. Ciofalo, CFD simulations of dense solid-liquid suspensions in baffled stirred tanks: Prediction of solid particle distribution, Chemical engineering journal, 223 (2013) 875-890.

[29] J. Hamer, Ballast Tank Sediments, in: E. Leppäkoski, S. Gollasch, S. Olenin (eds.) Invasive Aquatic Species of Europe. Distribution, Impacts and Management, Springer Netherlands, 2002, pp. 232-234.

[30] S. Gollasch, The importance of ship hull fouling as a vector of species introductions into the North Sea, (2002).

[31] A. Tamburini, A. Cipollina, G. Micale, A. Brucato, M. Ciofalo, CFD simulations of dense solid-liquid suspensions in baffled stirred tanks: Prediction of the minimum impeller speed for complete suspension, Chemical engineering journal, 193-194 (2012) 234-255.

[32] A. Tamburini, A. Cipollina, G. Micale, M. Ciofalo, A. Brucato, Dense solid-liquid offbottom suspension dynamics: Simulation and experiment, Chemical Engineering Research and Design, 87 (2009) 587-597.

[33] A. Tamburini, A. Cipollina, G. Micale, A. Brucato, M. Ciofalo, CFD simulations of dense solid-liquid suspensions in baffled stirred tanks: Prediction of suspension curves, Chemical Engineering Journal, 178 (2011) 324-341. 